$\left.\right|_{\text {Mason \& Hanger- }}$

MHSMP- $-70-10 \quad B$

Silas Mason Gro, Inn.

ENGINEERS AND CONTRACTORS

SINCE 1B2T

Pantex Plant

HE FORMULATION

SANLS 712-003 \& 008

A. G. Osborn

April, May, June 1970 


\section{DISCLAMIER}

Portions of this document may be illegible in electronic image products. Images are produced from the best available original document. 


\title{
HE FORMULATION
}

\author{
A. G. Osborn \\ April, May, June 1970 \\ SANLS 712-003 \& 008
}

\begin{abstract}
Micronized PETN was subjected to temperatures above $212^{\circ} \mathrm{F}$ for time periods of 2 to 8 hours to determine if the previous 300 -hour cycle could be shortened. It appears that PETN is effectively stabilized after 8 hours at $240^{\circ} \mathrm{F}$.

Other PETN samples were treated with wetting agents and also subjected to $240^{\circ} \mathrm{F}$ for 8 hours. Seven of the twelve treated samples showed a substantial increase in stabilized surface area with the highest being $16,850 \mathrm{~cm}^{2} / \mathrm{g} \mathrm{S}_{0}^{P}$ after being washed with Stein Hall's Jaguar J2S1. Untreated surface area was $5,000 \mathrm{~cm}^{2} / \mathrm{g} \mathrm{S}_{0}^{\mathrm{P}}$.
\end{abstract}

\section{DISCLAIMER}

This report was prepared as an account of work sponsored by an agency of the United States Government. Neither the United States Government nor any agency thereof, nor any of their employees, makes any warranty, express or implied, or assumes any legal liability or responsibility for the accuracy, completeness, or usefulness of any information, apparatus, product, or process disclosed, or represents that its use would not infringe privately owned rights. Reference herein to any specific commercial product, process, or service by trade name, trademark, manufacturer, or otherwise does not necessarily constitute or imply its endorsement, recommendation, or favoring by the United States Government or any agency thereof. The views and opinions of authors expressed herein do not necessarily state or reflect those of the United States Government or any agency thereof. 


\section{DISCUSSION}

$S_{0}^{P}$ Stabilization at $>100^{\circ} \mathrm{C}$

In the past, a few PETN samples which were heated at or near $240^{\circ} \mathrm{F}$ for several hours exhibited a high degree of surface area stability, suggesting the shortening of the long 300 -hour cycle at $212^{\circ} \mathrm{F}$. At that time some questions arose concerning the accuracy and cycling of the ovens. Therefore, the ovens were calibrated and steam control valve positioners installed to minimize cycling and enhance response. Control is now very fine, with cycling undetectable on the circular chart recorders. With this improvement, a much more comprehensive heat aging study was initiated.

The study consisted of heating samples at temperatures from $220^{\circ} \mathrm{F}$ to $240^{\circ} \mathrm{F}$ in $5^{\circ}$ increments for $2,4,6$, and 8 hours at each temperature. This makes a total of 20 different combinations of time and temperature. To verify or to determine the extent of change or stabilization, samples were withdrawn after completing each condition and further subjected to a 300 hour $/ 212^{\circ} \mathrm{F}$ test cycle. Results, along with a control sample, are given in Table I and plotted in Figs. 1 through 4.

Figs. 1, 2, and 3 show the results of the high temperature aging plus the postaging 300 -hour $/ 212^{\circ} \mathrm{F}$ heat cycle for each condition. The control sample heated only at $212^{\circ} \mathrm{F}$ for 300 hours is also shown in Fig. 3. (In Figs. 1, 2, and 3, except for the control sample, the upper portions of the curves from 7,500 to $18,200 \mathrm{~cm}^{2} / \mathrm{g}$ were omitted.) As shown by the flatter curve, Fig. 3 , the most stable sample was obtained at $240^{\circ} \mathrm{F}$ for 8 hours. In Fig. 4, upper plot, the surface areas obtained from the high temperature short cycles are again presented, collectively for comparison. The lower plot, Fig. 4, is very intr.esting; it is a plot of the 300 -hour $212^{\circ} \mathrm{F}$ test cycle and depicts the $220^{\circ} \mathrm{F}:$ lours sample starting at a higher surface area than the $240^{\circ} \mathrm{F} / 8$ hour sample, yet 
Fig. 1
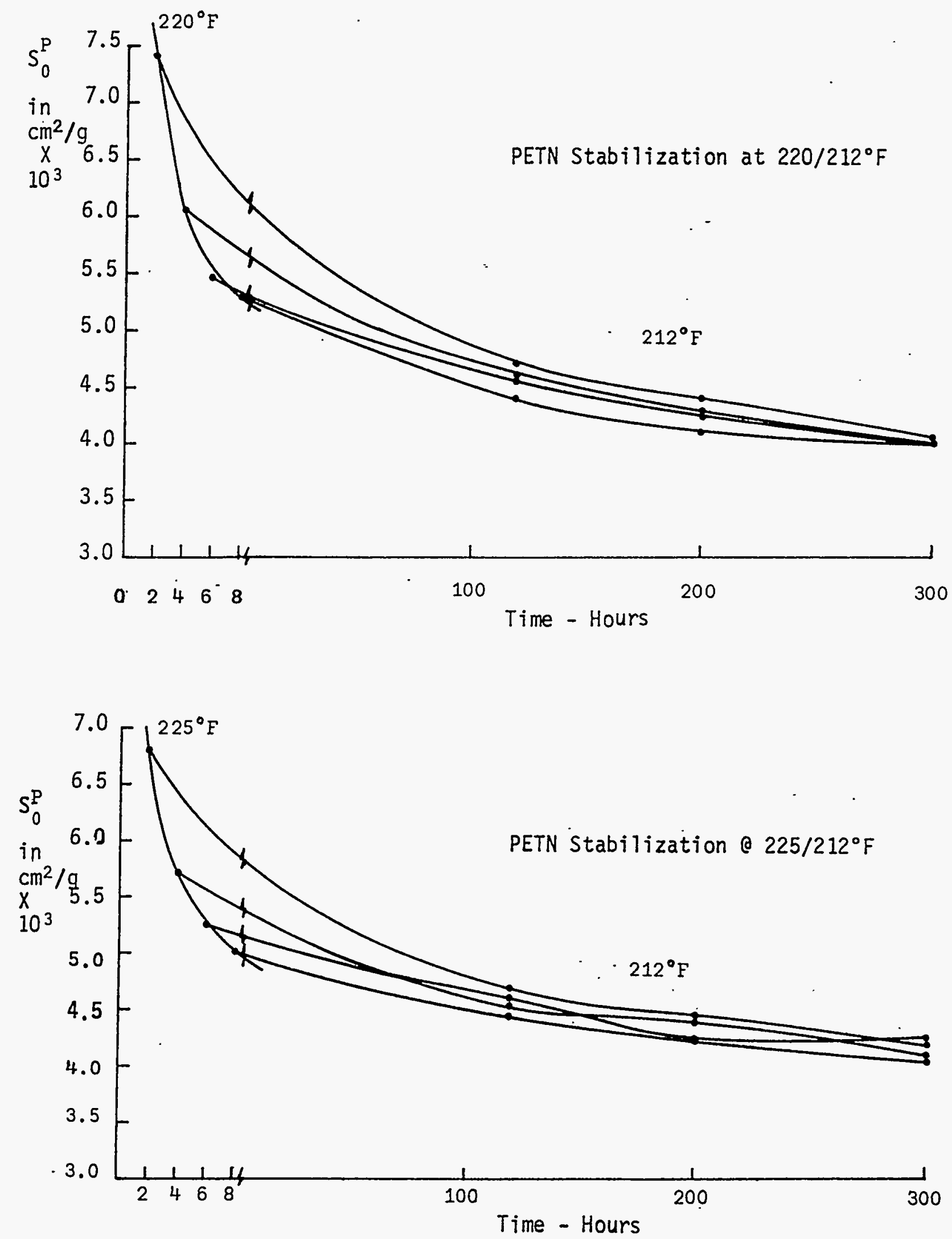
Fig. 2
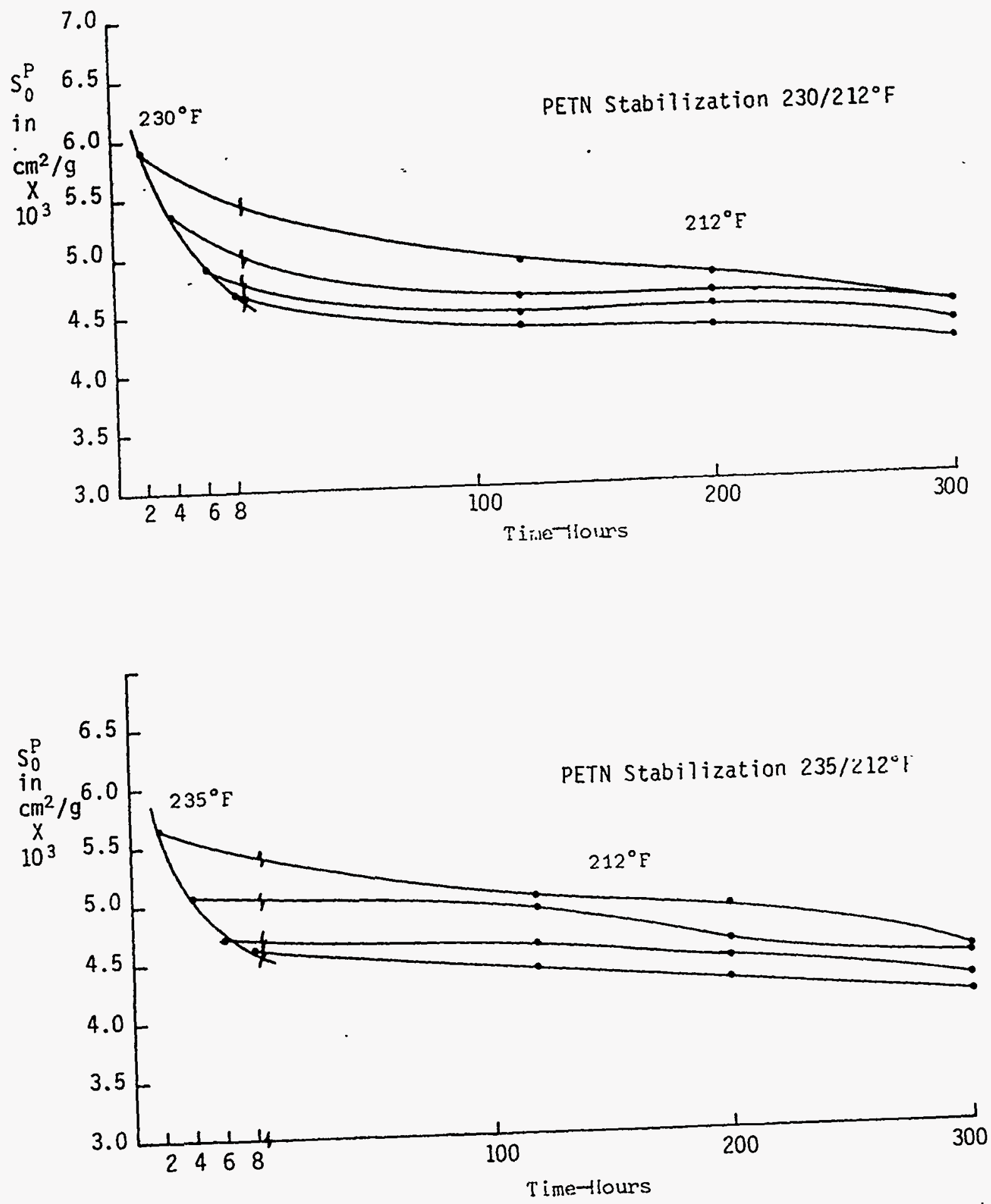

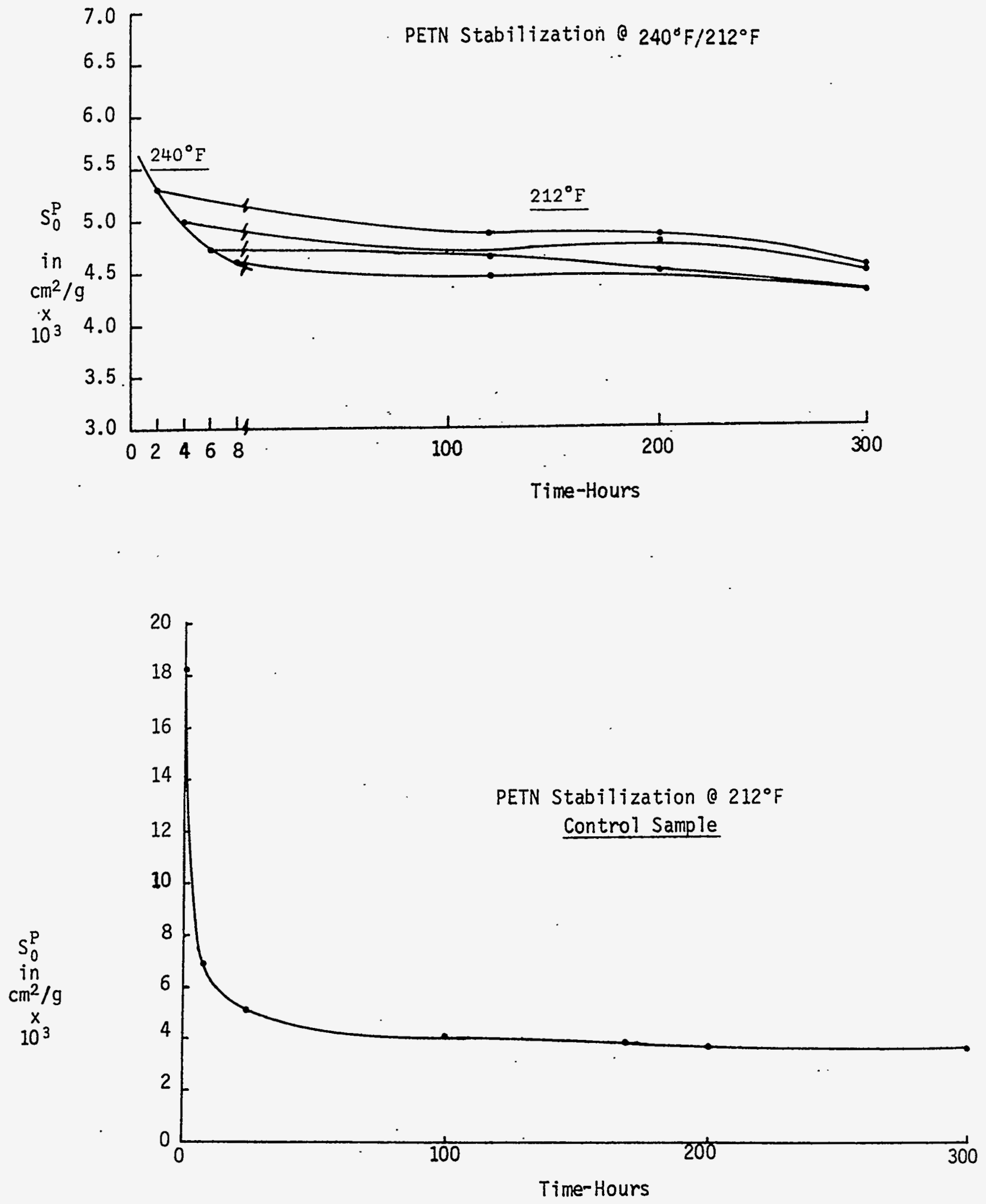

Fig. 3 

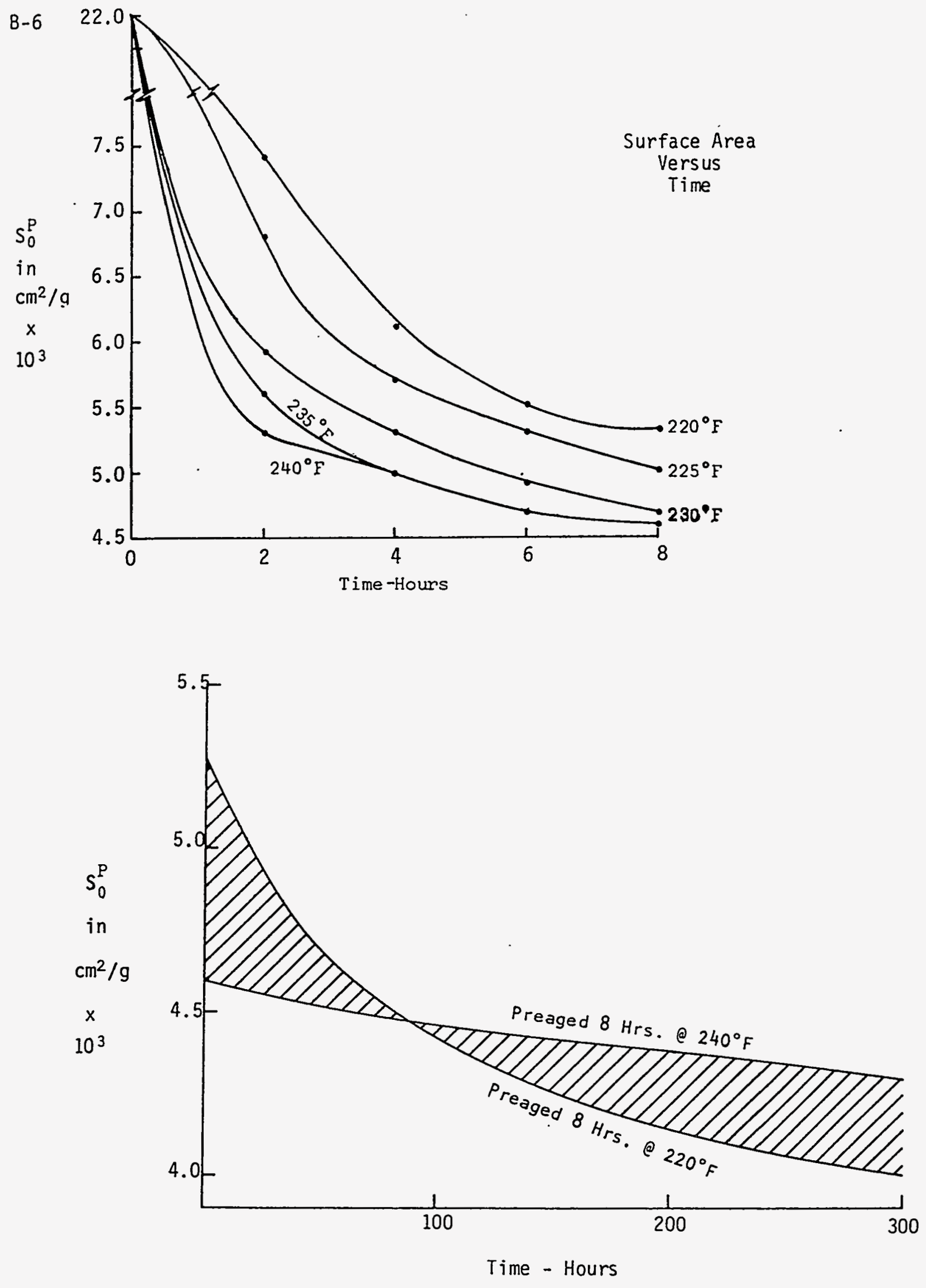

Fig. 4

Exposure at $212^{\circ} \mathrm{F}$ After Pre-aging at $\mathrm{Higher}$ Temperature 
finishing at a lower surface area. The differences in surface areas are smallon the order of 300 to $700 \mathrm{~cm}^{2} / \mathrm{g}$-but the pattern may be observed in almost every case, as may be seen in Table I and by comparing samples heated for the same time periods: the sample initially subjected to the higher temperature starts at a lower surface area, yet finishes higher. That is true at any heating time, whether 2, 4, 6, or 8 hours, suggesting that the higher the temperature (within limits of course) the higher the final stabilized surface area. This idea is also supported by the control sample data. It was heated at the lowest temperature, $212^{\circ} \mathrm{F}$, and stabilized at the lowest surface area, $3650 \mathrm{~cm}^{2} / \mathrm{g} \mathrm{S}_{0}^{P}$.

Fig. 5 contains photomicrographs of the stabilized control sample, sample heated at 8 hours $/ 240^{\circ} \mathrm{F}$, and, then at 8 hours $/ 240^{\circ} \mathrm{F}$ plus $300 / 212^{\circ} \mathrm{F}$.

Effect of Wetting Agents on $S_{0}^{P}$ Stabilization

A study of the stabilizing effect of wetting agents is also being conducted. Twelve have been tried and eight others have been received. The presence of certain types of large molecules on the crystal surface should interfere with the surface activity resulting in less growth and crystal change. Work conducted in the past with sodium dodecyl sulfate and sodium hexadecyl sulfate suggested that.stabilization is more than a possibility, well within the reach of reality. The survey this quarter year is simply for the purpose of picking the most promising prospects for further work. For each agent, a sample of approximately $200 \mathrm{~g}$ of Micronized PETN was collected in the centrifuge and subsequently washed with three gallons of water containing $200 \mathrm{ppm}$ of wetting agent, 
PETN Surface Area $\left(S_{0}^{P} \mathrm{~cm}^{2} / \mathrm{g}\right)$

Stabilization Study 0145-304M-01

Control Sample Heated o $212^{\circ} \mathrm{F}$

\begin{tabular}{c|c|c|c|c|c|c}
\hline Initial $\mathrm{S}_{0}^{\mathrm{P}}$ & $8 \mathrm{Hrs}$. & $24 \mathrm{Hrs}$ & $100 \mathrm{Hrs}$. & $168 \mathrm{Hrs}$ & $200 \mathrm{Hrs}$. & $300 \mathrm{Hrs}$. \\
\hline 18250 & 6900 & 5100 & 4100 & 3700 & 3700 & 3650 \\
\hline
\end{tabular}

\begin{tabular}{ll}
\multicolumn{2}{r}{$220^{\circ} \mathrm{F}$} \\
\hline $2 \mathrm{Hrs.}$ & 7400 \\
$4 \mathrm{Hrs.}$ & 6050 \\
$6 \mathrm{Hrs.}$ & 5450 \\
$8 \mathrm{Hrs}$. & 5300
\end{tabular}

\begin{tabular}{c|c|c}
\multicolumn{3}{c}{$212^{\circ} \mathrm{F}$} \\
\hline 119 Hrs. & 199 Hrs. & 300 Hrs. \\
\hline 4700 & 4400 & 4050 \\
4600 & 4300 & 4000 \\
4550 & 4250 & 4000 \\
4400 & 4100 & 4000
\end{tabular}

\begin{tabular}{ll}
\multicolumn{2}{r}{$225^{\circ} \mathrm{F}$} \\
\hline $2 \mathrm{Hrs}$. & 6800 \\
$4 \mathrm{Hrs}$. & 5700 \\
$6 \mathrm{Hrs}$. & 5250 \\
8 Hrs. & 5000
\end{tabular}

\begin{tabular}{ll}
\multicolumn{2}{r}{$230^{\circ} \mathrm{F}$} \\
\hline 2 Hrs. & 5900 \\
4 Hrs. & 5350 \\
6 Hrs. & 4900 \\
8 Hrs. & 4700
\end{tabular}

4700

4550

4600

4450

4900

4600

4450

4350

5000

4800

4600

4400

4850

4650

4650

4450
4450

4400

4250

4250

4750

4600

4500

4300

4900

4600

4450

4250

4850

4800

4500

4500
4200

4200

4250

4050

4450

4450

4300

4150

4500

4450

4250

4100

4550

4500

4300

4300 

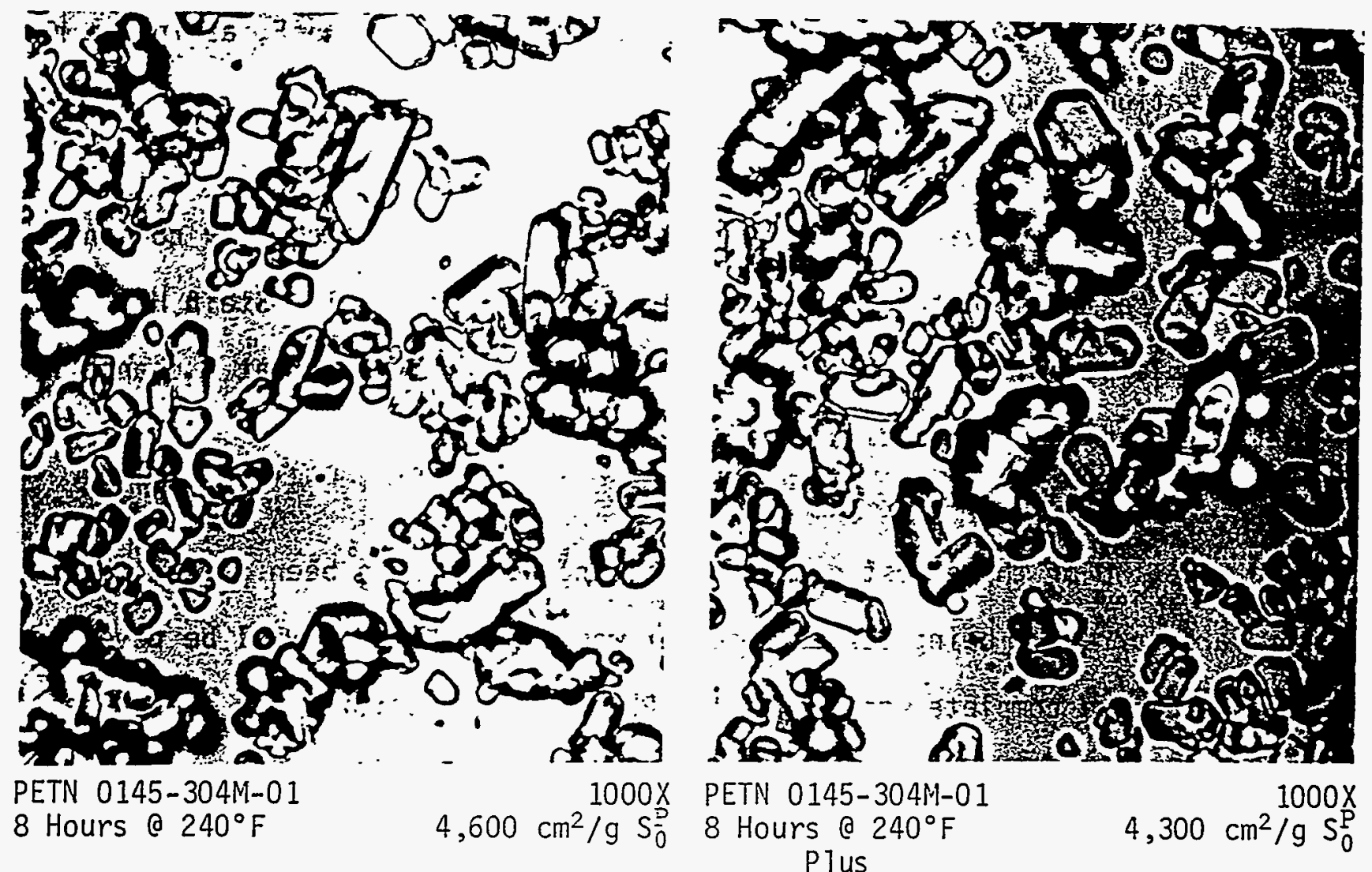

300 Hours $2212^{\circ} \mathrm{F}$

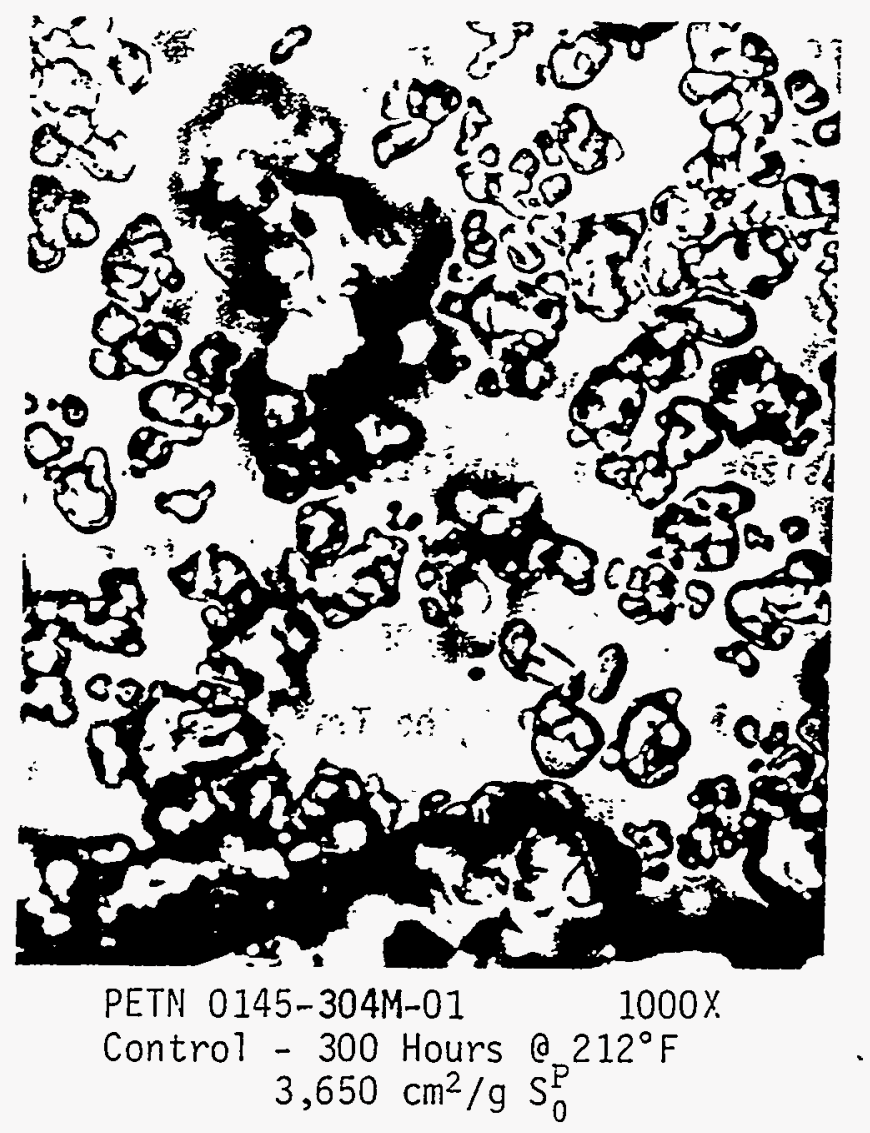

Fig. 5 


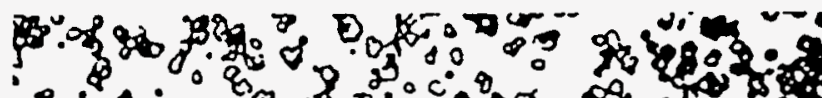

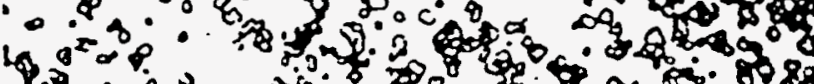
B $30^{2} 0_{0}$

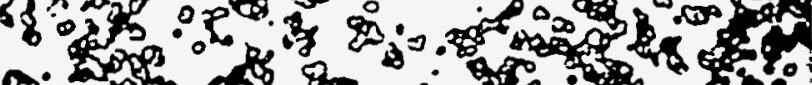
a. 20 3 0 . os 0

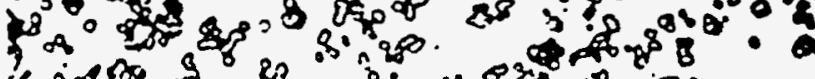
5 \%

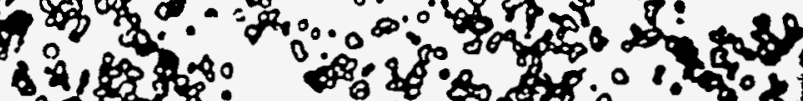

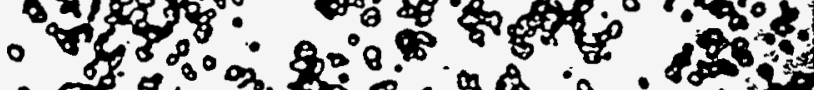

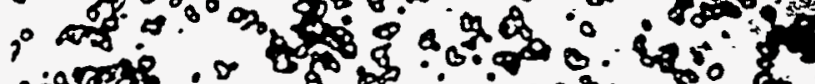

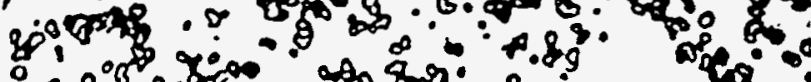

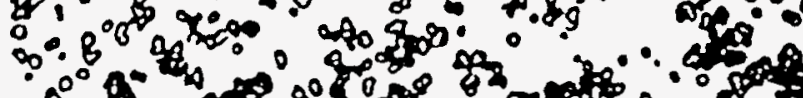

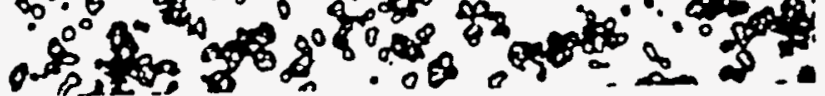

PETN 0174 304il-1C

$1000 x$

$$
19,650 \mathrm{~cm}^{2} / \mathrm{g} \mathrm{S}_{0}^{0}
$$

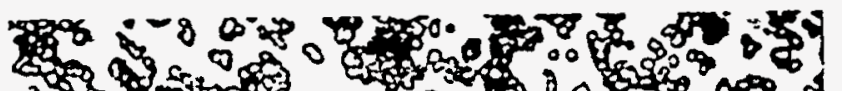
2. O 0.8 \% - 50 \%

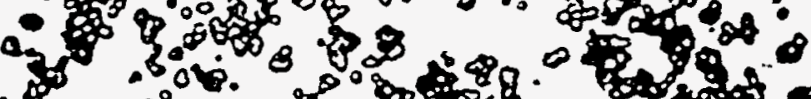

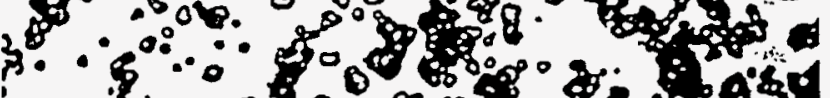
\%os $80^{\circ}$ 0.0 \& 4 it 3000 . iq 30 s of

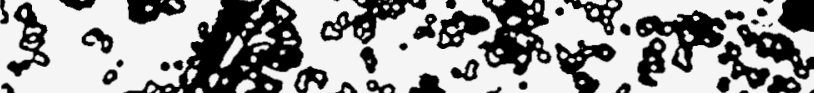
(4) \% .4 a foros PETN 0174 304it-JB

$1000 \mathrm{X}$

$$
24,300 \mathrm{~cm}^{2} / \mathrm{g} \mathrm{S}
$$
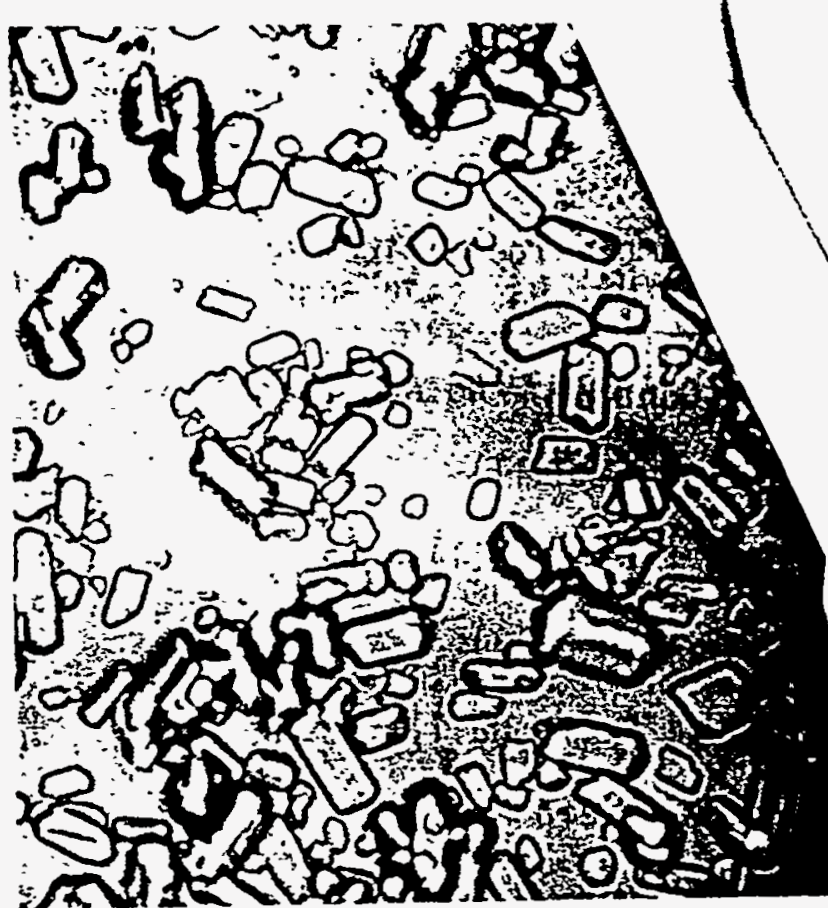

$1000 x$

PETN 0174 304M-IC $5,000 \mathrm{~cm}^{2} / g \mathrm{~S}_{0}^{\mathrm{P}}$

8 Hours $0240^{\circ} \mathrm{F}$
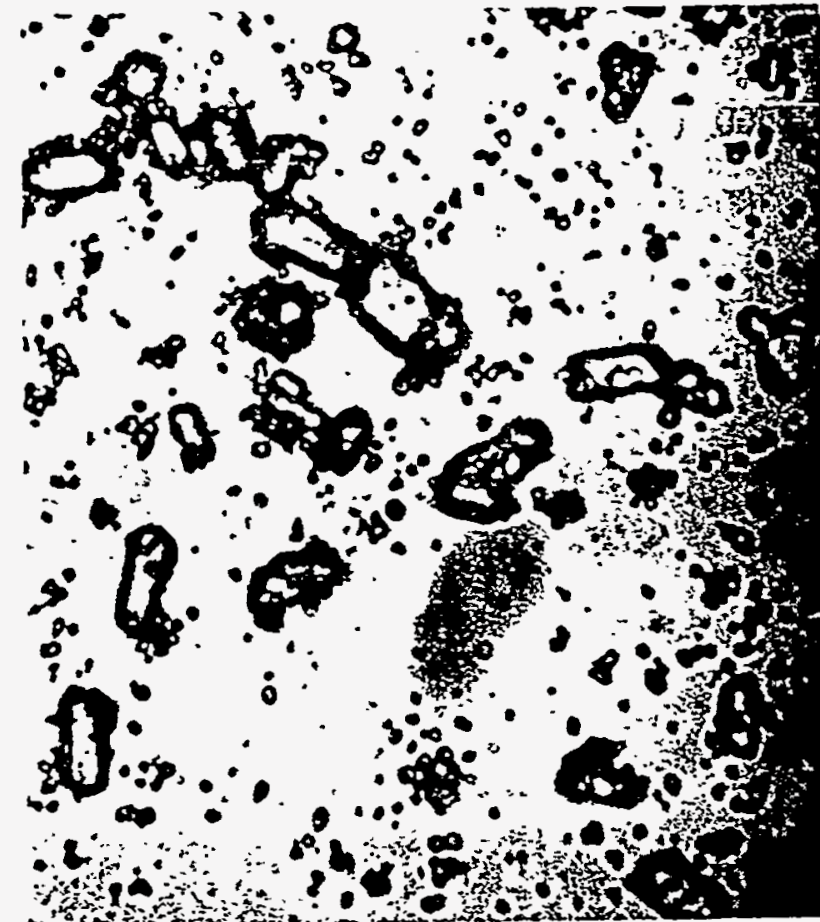

PETN 0174-304M-JB

$1000 x$

8 Hours $2040^{\circ} \mathrm{F}$

$11,600 \mathrm{~cm}^{2} / \mathrm{g} \mathrm{S}_{0}^{\mathrm{P}}$

Fig. 6 
\%

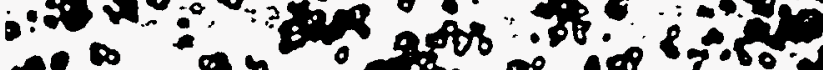
$40^{\infty} 0^{\circ}$.

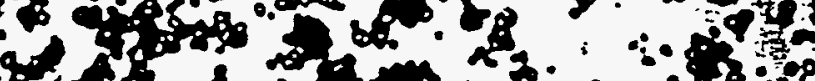

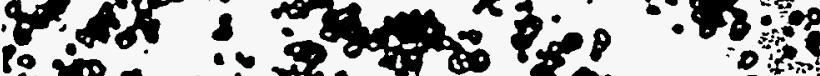

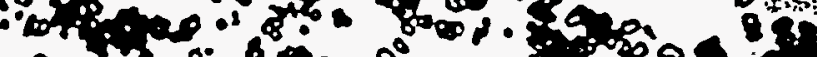
$100 \mathrm{c}$

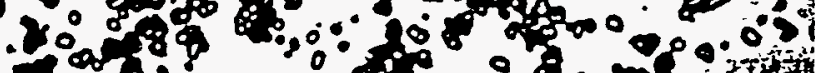
apo: .0

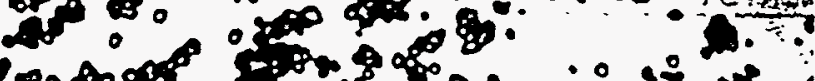

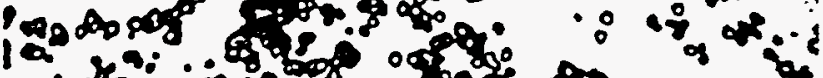
- bo or of $\because 00 . \therefore$ 8p of

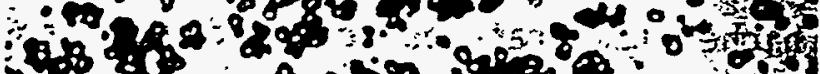
a $0.500 \% 000$

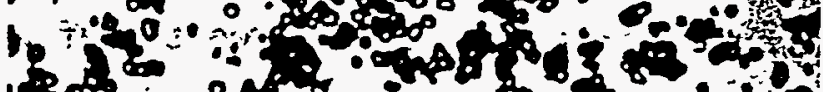

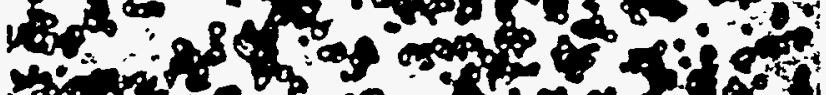

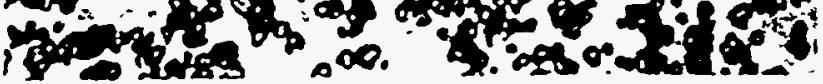
PETN 174-304:Y-J251

$$
23,400 \mathrm{~cm}^{2} / \mathrm{g} \mathrm{S}
$$

$1000 x$

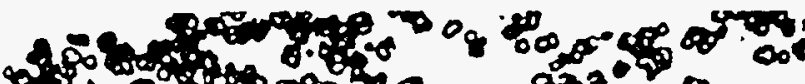

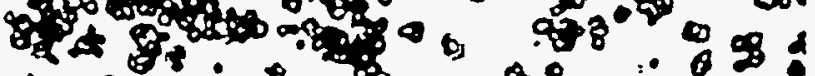
\%os. Pos.

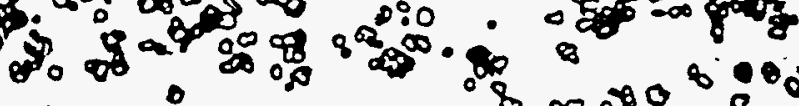
$80500 \cdot 80000000009$

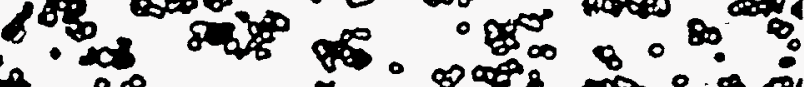

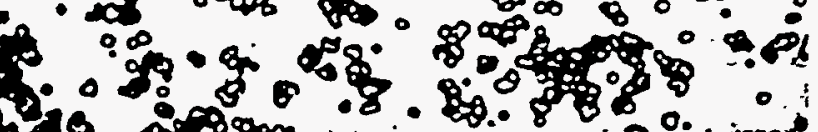

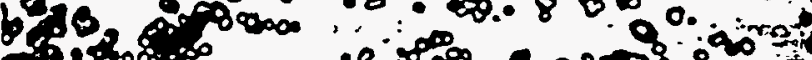

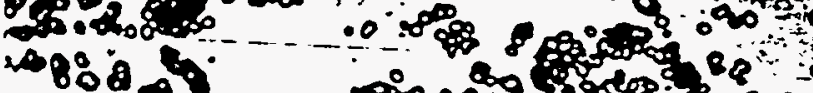
$0000.09000 \%$

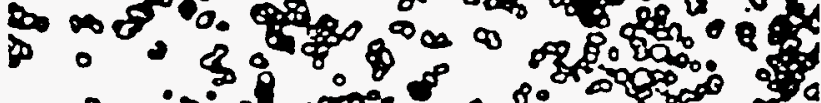

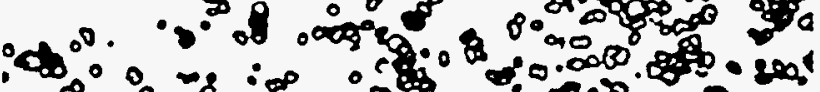

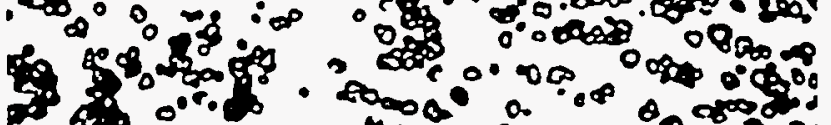
PETN 0174-304M-X100

$$
17,000 \mathrm{~cm}^{2} / \mathrm{g}
$$

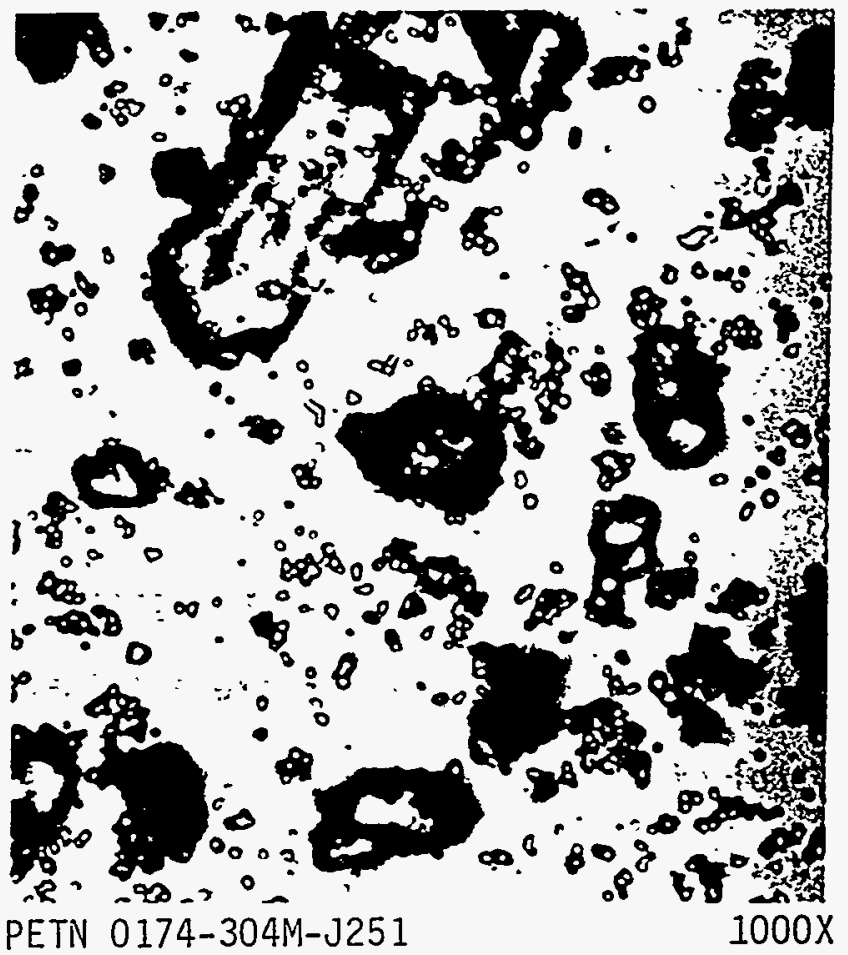

8 Hours o $240^{\circ} \mathrm{F}$ $16,850 \mathrm{~cm}^{2} / \mathrm{g} \mathrm{S}_{0}^{P}$

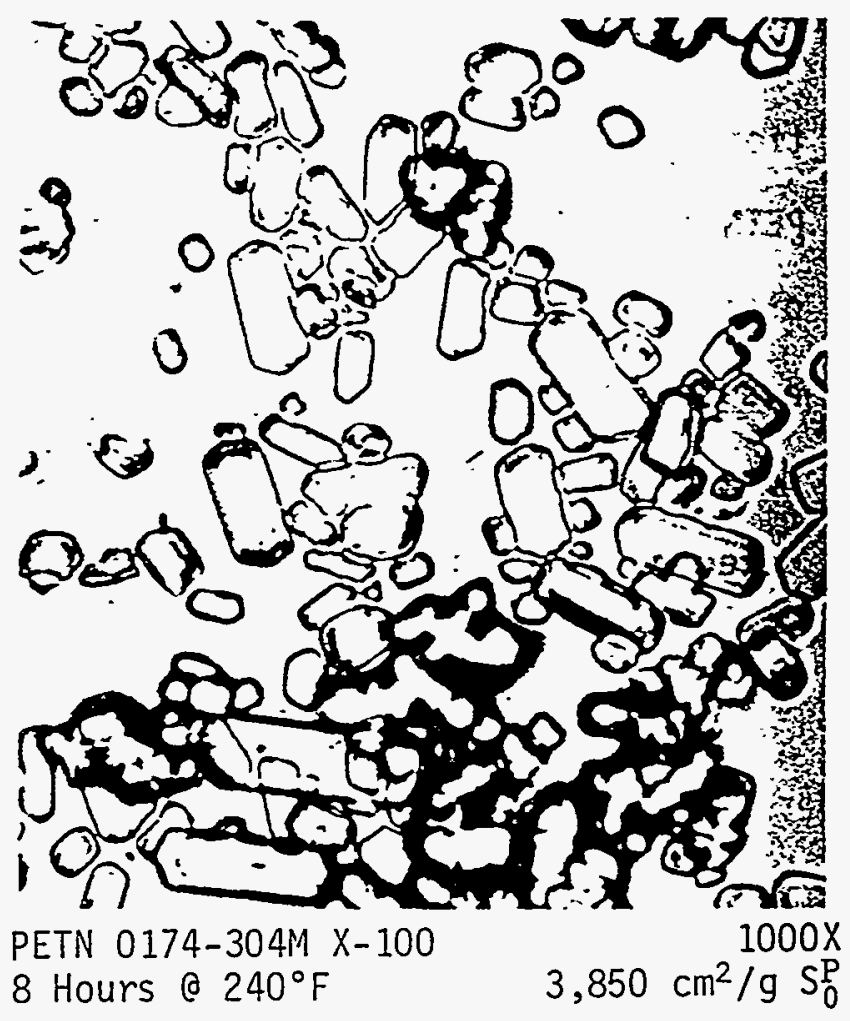

Fig. 7 


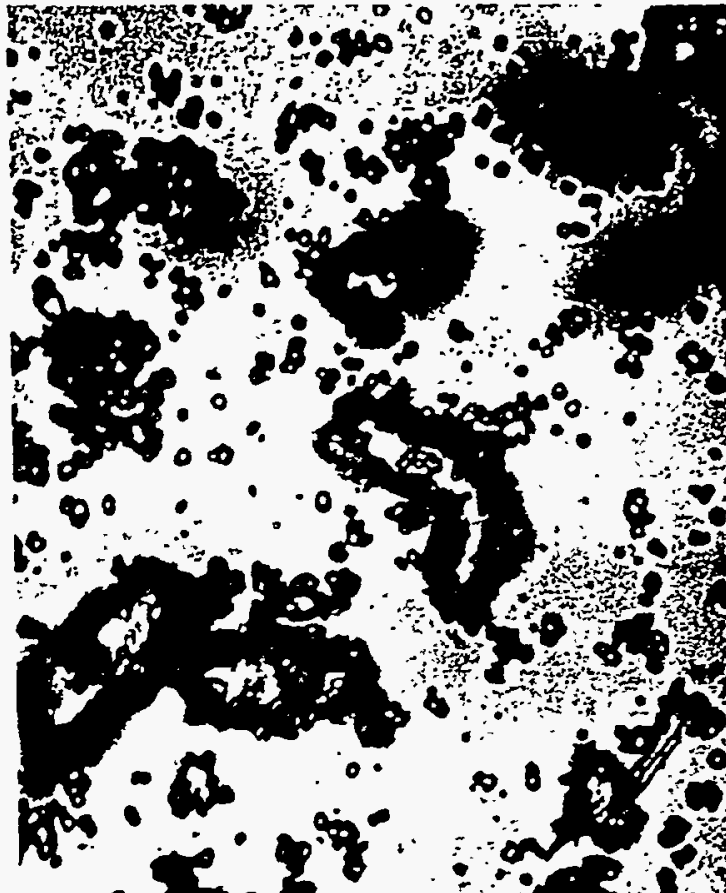

PETN $0174-304 \because-7050 E$

8 Hours $0240^{\circ} \mathrm{F}$

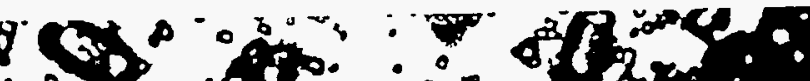

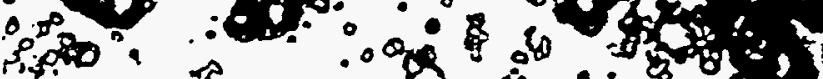

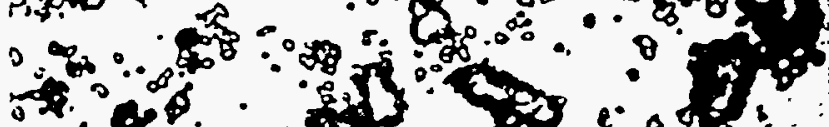
$\therefore 0$ \%

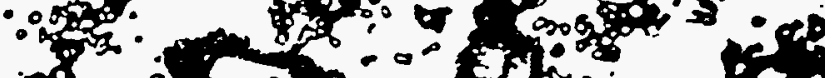

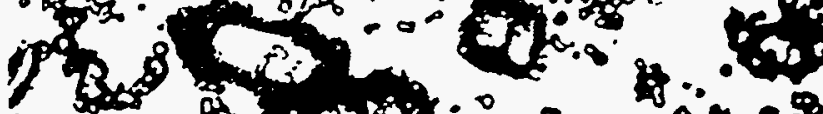
-

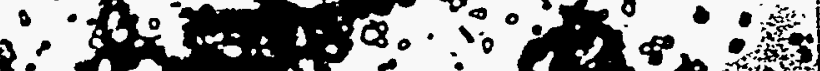

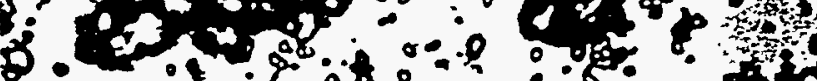

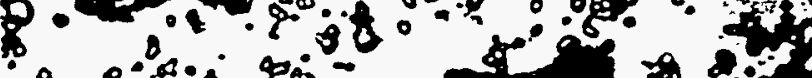

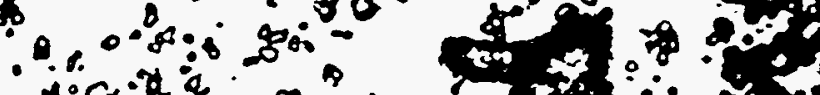
0 \}$^{\circ}: 08$ of

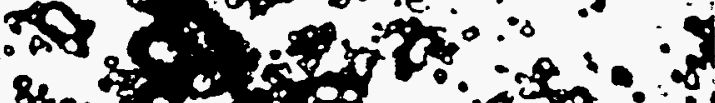

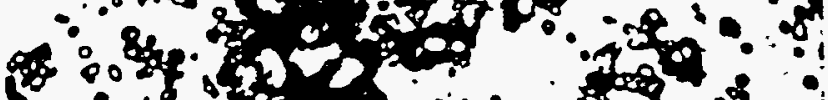

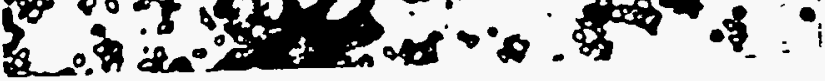

PETN 0174-30414-P]US 8 Hours $240^{\circ} \mathrm{F}$
$1000 x$ $12,200 \mathrm{~cm}^{2} / \mathrm{g} \mathrm{S}^{?}$
.06:-
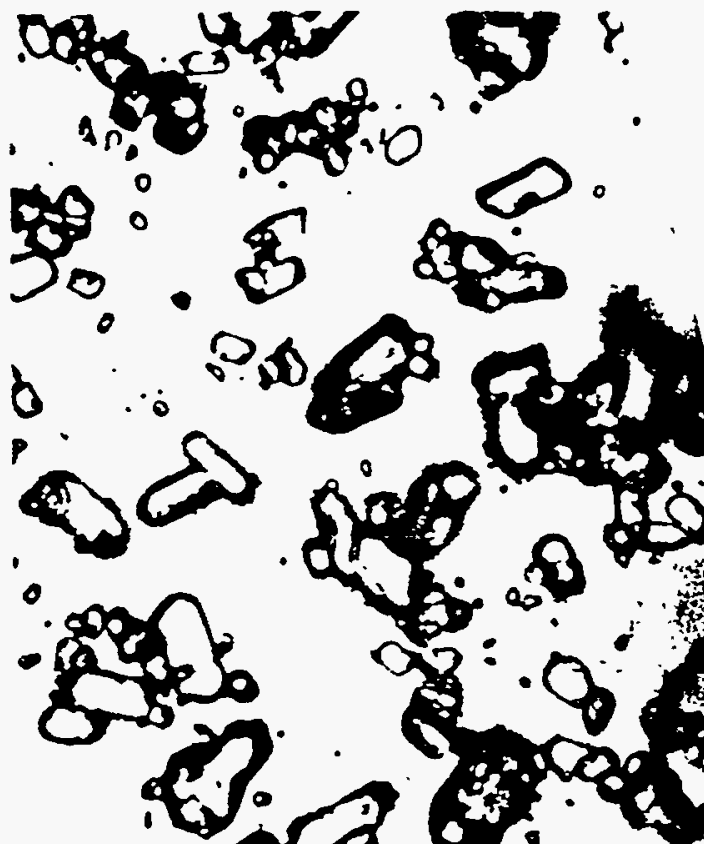

8

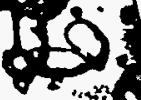

PETN 0174-304:-1212A
8 Hours $0240^{\circ} \mathrm{F}$
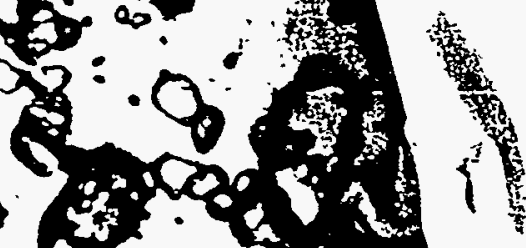

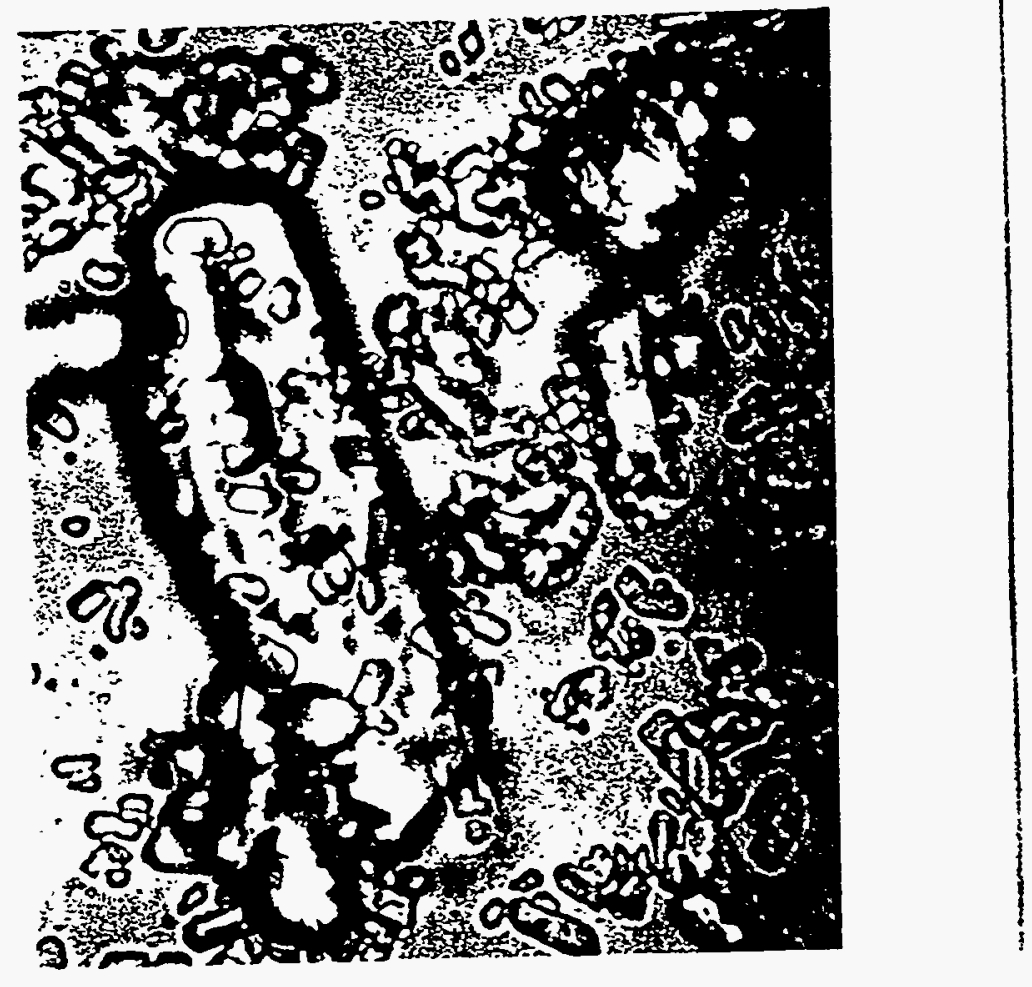

Fig. 8 